\title{
T Cell Stimulus-Induced Crosstalk between Lymphocytes and Liver Macrophages Results in Augmented Cytokine Release
}

\author{
Florian Gantner, ${ }^{*}$ Marcel Leist, ${ }^{*}$ Sabine Küsters, Katrin Vogt $\uparrow$ Hans-Dieter Volk, $\dagger$ And Gisa Tiegs ${ }^{1}$ \\ Institute for Experimental and Clinical Pharmacology and Toxicology, University Erlangen-Nürnberg, Universitätsstrasse 22, D-91054 \\ Erlangen, Germany; *Faculty of Biology, University of Konstanz, D-78464 Konstanz, Germany; and †Institute for Medical \\ Immunology, Charité, Humboldt University, D-10098 Berlin, Germany
}

\begin{abstract}
Polyclonal $\mathbf{T}$ cell stimulation in humans leads to a cytokine burst syndrome that may result in organ failure or lethality. Mechanisms of such cytokine-dependent morbidity can be studied in mice challenged with the $T$ cell mitogen concanavalin $A$ (Con A). In this model tumor necrosis factor (TNF)-dependent toxicity is characterized by a relatively selective liver failure. We examined here whether a crosstalk between liver macrophages and lymphocytes may be the underlying cause for the overshooting TNF response. Lymphocytes from Iymph nodes, thymus, or the spleen were cocultured with Kupffer cells and stimulated with the polyclonal $T$ cell stimuli Con $A$, anti-CD3 $\mathrm{mAb}$, or staphylococcal enterotoxin $B$. We observed a rapid and synergistically augmented release of TNF, and also of IL-1, IL-2, IL-4, IL-6, and IFN- $\gamma$, compared to stimulation of the individual cell types alone. This dramatically upregulated cytokine response did not require direct cell contact, but was mediated by a soluble factor. In order to find out whether TNF upregulation would require additional cell types in the liver, we used cocultures of $T$ cells and a macrophage cell line and confirmed our previous results. In this model system an increase in TNF mRNA was observed in macrophages, but not in $T$ cells. We conclude that the $T$ cellmacrophage crosstalk following polyclonal T cell stimulation may be responsible for an overshooting TNF release from macrophages. This mechanism finally may lead to organ damage such as liver injury upon Con A injection into mice.
\end{abstract}

\section{INTRODUCTION}

Many diseases, autoimmune reactions, and the systemic inflammatory response syndrome (SIRS) [1] are the result of a dysregulated cytokine response during infection or inflammatory processes [2]. Overproduction of cytokines may lead to organ damage, while inhi-

\footnotetext{
${ }^{1}$ To whom correspondence and reprint requests should be addressed. Fax: 49-9131-206119.
}

bition impairs defense capacities. For example, the overproduction of TNF, ${ }^{2}$ one of the central mediators in various acute inflammatory processes, causes organ dysfunction such as liver damage [3-5]. On the other hand, diminished production or impaired action of IFN$\gamma$ [6], IL-12 [7], or TNF [8, 9] leads to an increased susceptibility to infections.

Acute organ damage due to in vivo activation of $\mathrm{T}$ cells has been studied recently in various mouse models. In mice sensitized by D-galactosamine, stimulation of the $\mathrm{T}$ cell response with anti-CD3 monoclonal antibodies $(\mathrm{mAb})[10]$ or the superantigen staphylococcal enterotoxin B (SEB) [5] caused liver injury that was mediated by cytokines. In another model using nonsensitized mice, injection of the $\mathrm{T}$ cell mitogen Con A alone evoked a selective liver failure when given intravenously. $\mathrm{CD} 4^{+} \mathrm{T}$ cells as well as macrophages were identified as necessary effector cells [11, 12]. The cytokine TNF and its 55-kDa receptor [13] play a pivotal role in the development of liver injury in these animal models $[5,12,14]$. However, the cellular sources of circulating TNF and the regulation of its release under these inflammatory conditions have not been elucidated due to the experimental limitations of in vivo studies.

Lymphocytes are the primary target cells of the $\mathrm{T}$ cell mitogen Con $\mathrm{A}$, and liver cells are the ultimate targets of cytokine-induced hepatic injury following Con A injection into mice. In order to investigate mechanisms of cytokine release within the liver after $\mathrm{T}$ cell activation, we studied the in vitro interaction of liver cells and lymphocytes during stimulation with Con A. It is well established that macrophage-T cell interactions are a necessary basis for many immune reactions. Macrophages function as antigen presenting cells, as producers of inflammatory cytokines, and as thiol donors $[15,16]$. Commonly these interactions require a

\footnotetext{
${ }^{2}$ Abbreviations used: $\alpha-\mathrm{MM}, \alpha$-methylmannopyranoside; Con $\mathrm{A}$, concanavalin A; KC, Kupffer cells; LACT, lymphocyte augmented Con A-induced TNF release; LNC, lymph node cells; NPC, nonparenchymal liver cells; TNF, tumor necrosis factor; WLC, whole liver cells; SEB, staphylococcal enterotoxin B; SLC, spleen cells; TC, thymocytes.
} 
specific cell contact mediated by surface molecules, e.g., by $\mathrm{T}$ cell receptor-MHC (major histocompatibility complex) interactions, by superantigens [reviewed in 17], or by interaction among $\beta 2$-integrins, CD69, and CD2 [18]. These interactions mostly result in long-term effects, such as cytokine production (24-72 $\mathrm{h}$ after stimulation), induction of metalloproteinases [19, 20], or proliferation of $\mathrm{T}$ cells. To our knowledge a rapid crosstalk that is mediated by a soluble factor(s) only and that results in dramatically augmented production of inflammatory mediators within a few hours has not been reported. In this study we present results on the cytokine crosstalk between the major effector cell populations involved in immunologically mediated liver damage in Con A-challenged mice, i.e., lymphocytes and macrophages.

\section{MATERIALS AND METHODS}

\section{Reagents}

LPS, Con A, SEB (S 4881), and $\alpha$-methylmannopyranoside ( $\alpha$-MM) were purchased from Sigma (Deisenhofen, Germany); anti-CD3 mAb (clone 145 2C11, hamster IgG) was from Pharmingen (San Diego, CA). The murine soluble IL-4 receptor was kindly provided by Dr. Karlheinz Enßle (Behringwerke AG, Marburg, Germany).

\section{Animals}

Male BALB/c albino mice were purchased from the animal house of the University of Konstanz (Germany). Male BALB/c nude mice were purchased from Harlan (Austerlitz, The Netherlands). Mice carrying a disrupted gene for the IFN- $\gamma$ receptor (ifn $\gamma-r^{\circ}$ mice [6]) were kindly provided by Dr. Horst Bluethmann (Hoffmann-La Roche, Basel, $\mathrm{CH}$ ) with the courtesy of Dr. Michel Aguet (Genentech Inc., South San Francisco, CA). All mice were kept at least 1 week at $22^{\circ} \mathrm{C}$ and $55 \%$ relative humidity in a 12 -h day/night rhythm with free access to food (Altromin 1313) and water. All animals received humane care according to German law.

\section{J774 Cells}

The murine macrophage cell line J774 (American Type Culture Collection designation TIB 67) was kept in culture by seeding the cells in culture flasks containing RPMI 1640 medium (Biochrom, Berlin, Germany) supplemented with $10 \%$ fetal calf serum (FCS) and the antibiotics penicillin $(100 \mathrm{U} / \mathrm{ml})$ and streptomycin $(100 \mu \mathrm{g} / \mathrm{ml})$. The confluently growing cells were harvested using a rubber policeman every 2-3 days after start of culture, washed, and seeded in fresh medium. For stimulation experiments, cells were seeded at a density of $5 \times 10^{5}$ cells $/ \mathrm{ml}$ overnight and stimulated as indicated. Under these conditions, basal release of TNF was below or at least near the detection limit of our bioassay.

\section{Cell Isolation}

Spleen, thymus, or lymph nodes (axillary, brachial, iliac, inguinal, facial, and superior mesenteric), respectively, from $\mathrm{BALB} / \mathrm{c}$ mice were removed and ground through a steel grid (diameter $100 \mu \mathrm{m}$ ) into $5 \mathrm{ml}$ RPMI 1640 medium.

Liver cells were isolated from 12 -week-old male BALB/c mice by the two-step collagenase perfusion method of Seglen [21] as modified by Klaunig [22]. After a $200 \mathrm{~g}$ and a $100 \mathrm{~g}$ centrifugation, liver cells were plated in $200 \mu$ l RPMI 1640 medium containing $10 \%$ newborn calf serum (NCS; Biochrom, Berlin, Germany) in 24-well plates at 8 $\times 10^{4}$ liver cells per well. Cells were allowed to adhere to culture plates for $5 \mathrm{~h}$ before the medium was exchanged for RPMI 1640 medium or RPMI 1640 medium containing lymph node cells (LNC), spleen cells (SLC) or thymocytes (TC). For cell separation experiments, LNC were added to the liver cell culture in membrane inlays (diameter $0.4 \mu \mathrm{m}$, Costar Transwell, Tübingen, Germany). Incubations were carried out for the times indicated in an incubator run at $5 \% \mathrm{CO}_{2}, 40 \% \mathrm{O}_{2}$, and $55 \% \mathrm{~N}_{2}$. Liver cell cultures contained $5 \%$ Kupffer cells, i.e., $1.6 \times 10^{3} /$ well as determined by latex phagocytosis or by unspecific esterase stain. Endothelial cell content (characterized by cytoskeletal staining) was below $1 \%$, since the coating conditions used do not favor endothelial cell attachment.

Nonparenchymal cells (NPC) were obtained by differential centrifugation from the liver cell suspension after collagenase digest. Supernatants from two successive $100 \mathrm{~g}$ centrifugations of liver cells were pooled and centrifuged for $8 \mathrm{~min}$ at $400 \mathrm{~g}$. The pellet contained the NPC fraction. NPC were washed twice and plated out at $2 \times 10^{5}$ cells/well in $200 \mu \mathrm{l}$ RPMI $1640+10 \%$ NCS. After a plastic adherence phase of $1 \mathrm{~h}$, supernatants were removed and exchanged for RPMI 1640 or RPMI 1640 containing lymph node cells. After the adherence step $1 \times 10^{5}$ NPC stuck to the culture plate, containing 80-90\% Kupffer cells and $\leqslant 0.5 \%$ hepatocytes.

\section{Cytokine Determination}

Protein. IFN- $\gamma$, IL-4, and IL-6 were determined by ELISA performed in flat-bottomed polystyrene microtiter plates (Greiner, Nürtingen, Germany). All antibodies (specific rat anti-murine $\mathrm{mAb}$ ) were purchased from Pharmingen. TNF was measured in a bioassay using the murine fibrosarcoma cell line WEHI 164 clone 13 according to Espevik and Nissen-Meyer [23]. IL-2 was determined in a cell proliferation assay according to Tada et al. [24], with the modification of using the mouse cytotoxic T cell line CTLL-2. Interleukin-1 (IL-1) was determined according to Hopkins and Humphreys [25] using a cellular assay based on the IL-1-dependent proliferation of the murine T-helper cell line D10N. Cytokine concentrations determined in the bioassays were calculated by the use of murine standards, and specificity was obtained by co-incubation with the respective antibodies (monoclonal anti-mouse IL- $1 \alpha$, monoclonal anti-mouse IL- $1 \beta$, monoclonal anti-mouse IL-2 antibodies, all from Genzyme (Cambridge, MA), and polyclonal sheep anti-mouse TNF $\alpha$ antiserum from our laboratory). All samples for cytokine determination were frozen at $-70^{\circ} \mathrm{C}$ until further use.

$m R N A$. RNA was extracted as described earlier [26]. Total cellular RNA $(1 \mu \mathrm{g})$ was reverse transcribed in a volume of $20 \mu \mathrm{l}$ using random primers and MMLV reverse transcriptase according to the supplier's recommendation (Gibco/BRL, Eggenheim, Germany).

Quantitative PCR: TNF-specific mRNA expression was quantified by PCR using a multispecific control fragment as internal standard as described previously [26]. In brief, known amounts of control fragment were added in different dilutions to unknown fixed amounts of cDNA for competitive coamplification with specific primers. The proportion of PCR products amplified from control fragment and target cDNA was estimated after separation on $1.5 \%$ agarose gels by measuring the intensity of ethidium bromide luminescence with a CCD image sensor and analyzed using the EASY program (Herolab, Wiesloch, Germany). First, the various cDNA samples to be compared were equilibrated according to their GAPDH cDNA content. Then, the relative concentration of TNF cDNA in each sample was estimated from the concentration of control fragment DNA which achieved equilibrium between its own amplification and that of the TNF cDNA. The concentrations were expressed in AU (arbitrary units). One $A U$ was defined as the lowest concentration of the control fragment which yielded a detectable amplification product (1 $\mathrm{AU}=$ dilution of control fragment $=10^{8}$ ).

\section{Cytokine Neutralization Experiments}

In order to block bioactivity of the cytokines produced in cell cultures, cells were incubated with the respective antibody $15-30 \mathrm{~min}$ 
prior to stimulation. All antibodies used were monospecific and of high bioactivity neutralizing capacity as determined by ourselves in in vivo experiments or bioassays (not shown).

\section{Conditioned Supernatants}

Supernatants from Con A-stimulated lymphocytes were collected at different time points $1-16 \mathrm{~h}$ after addition of Con $\mathrm{A}$. They were directly transferred to parallel liver cell cultures or frozen at $-80^{\circ} \mathrm{C}$ until further use. Frozen supernatants were thawed without further manipulation and added to fresh liver cell cultures.

\section{Statistics}

Each incubation was performed in triplicate and repeated at least three times with similar results. The data were analyzed using the two-tailed Welsh test or Student's $t$ test when appropriate and $P<$ 0.01 was considered statistically significant.

\section{RESULTS}

\section{Con A-Induced TNF Release from T Cell/Liver Cell Cocultures}

Macrophages play an important role in the murine model of Con A-induced liver injury [11] and are gener-

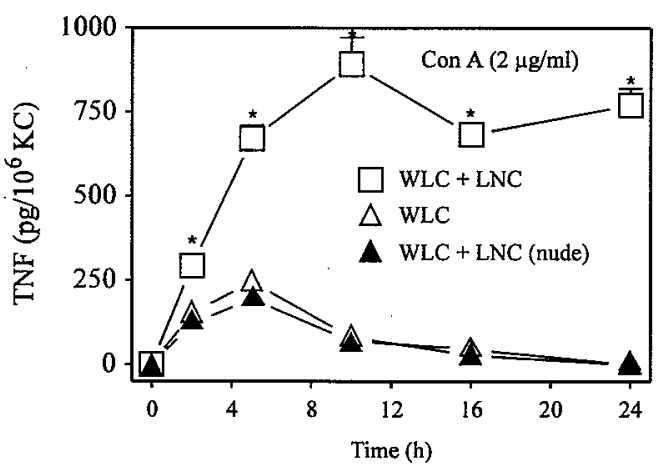

FIG. 2. Con A-induced TNF release from Kupffer cell-containing liver cell (WLC)/ymmph node cell (LNC) cocultures. Liver cells (WLC) were plated out at $8 \times 10^{4}$ hepatocytes/well (containing $5 \%$ Kupffer cells) for $5 \mathrm{~h}$ before supernatant was removed and exchanged for medium (open triangles) or for medium containing $1 \times 10^{6} \mathrm{LNC}$ from normal (open squares) or Con A-resistant nude mice (filled triangles). Con A was added at a final concentration of $2 \mu \mathrm{g} / \mathrm{ml}$. At the time points indicated supernatants were harvested and TNF bioactivity was determined. Data represent mean values $(n=3) \pm$ SEM. $* P<$ 0.01 vs control incubations without LNC or with LNC from nude mice.

ally considered to be the main TNF-producing cells in various inflammatory processes. The liver harbors the largest resident macrophage population in the body and is a potent producer of TNF [27]. We wondered whether Con A may directly induce cytokine release from these cells. TNF concentrations were not significantly increased (compared to the basal production of unstimulated controls) in supernatants of Kupffer cellcontaining liver cells (whole liver cells, WLC) or Kupffer cell-enriched (80-90\% KC) NPC incubated for $24 \mathrm{~h}$ with various nontoxic concentrations of Con A (data not shown, cf. Fig. 2). In contrast to this, high amounts of bioactive TNF were found, when the potent macrophage stimulus LPS was used for the activation of Kupffer cells. This indicates that these WLC were able to produce the cytokine under appropriate experimental conditions (Fig. 1). Stimulation of freshly prepared LNC with Con A, LPS, or a combination thereof also failed to induce TNF release within $24 \mathrm{~h}$ (data not shown). Thus, neither cell population alone, i.e., neither Kupffer cells nor LNC, was capable of releasing TNF upon Con A stimulation in vitro under our experimental conditions.

When a coculture system consisting of Kupffer cellcontaining liver cells plus LNC was stimulated with Con A, high amounts of TNF were detected in supernatants. The time course of Con A-induced TNF release in the WLC/LNC coculture system is shown in Fig. 2. Two hours after Con A stimulation $(2 \mu \mathrm{g} / \mathrm{ml})$ TNF release was detectable in supernatants of WLC/LNC cocultures, and TNF concentrations increased continuously until they reached a plateau of about $900 \mathrm{pg}$ TNF/
FIG. 1. LPS-induced TNF release from primary murine Kupffer cell-containing liver cells (A) or liver nonparenchymal (NPC) cells B). Liver cells (WLC) were plated out at $8 \times 10^{4}$ hepatocytes/well (containing 5\% Kupffer cells (KC)) (A) and $2 \times 10^{5} \mathrm{NPC}$ (containing 80-90\% Kupffer cells) (B). Five hours later supernatants were removed and exchanged for medium containing LPS ( $10 \mu \mathrm{g} / \mathrm{ml}$ final concentration) or the corresponding volume of pyrogen-free saline. At the time points indicated, supernatants were sampled and TNF bioactivity was calculated per $10^{6} \mathrm{KC}$ in the respective culture. Data represent mean values $(n=3) \pm$ SEM. ${ }^{*} P<0.01$ vs saline control 
$10^{6}$ Kupffer cells $10 \mathrm{~h}$ after stimulation. These high TNF concentrations remained in the medium of the coculture until the experiment was terminated at 24 h. In contrast, TNF levels started to decline to unstimulated control values after $5-10 \mathrm{~h}$ in WLC cultures stimulated with LPS (Fig. 1) and was not modulated by the addition of lymphocytes (not shown). Thus, with respect to TNF release from Kupffer cells, mechanistic differences seem to exist between the Kupffer cell stimulator LPS and the T cell activator Con A, with the latter being dependent on the presence of $T$ cells.

This lymphocyte-augmented Con A-induced TNF release (LACT) was concentration dependent from about 0.5 to $5 \mu \mathrm{g} / \mathrm{ml}$, until cytotoxic Con A concentrations were reached. Further experiments were carried out at a Con A concentration of $2 \mu \mathrm{g} / \mathrm{ml}$.

\section{Requirement of Kupffer Cells and Lymphocytes Only}

For further investigations on the role of LNC for this synergistic effect of Con A-induced TNF release in the liver cell/LNC coculture system, initially two different types of liver cell preparations were used. Kupffer cellenriched liver cell fractions (NPC) were compared to whole liver cell cultures (WLC) in order to gain information on a possible role of the hepatocytes them-
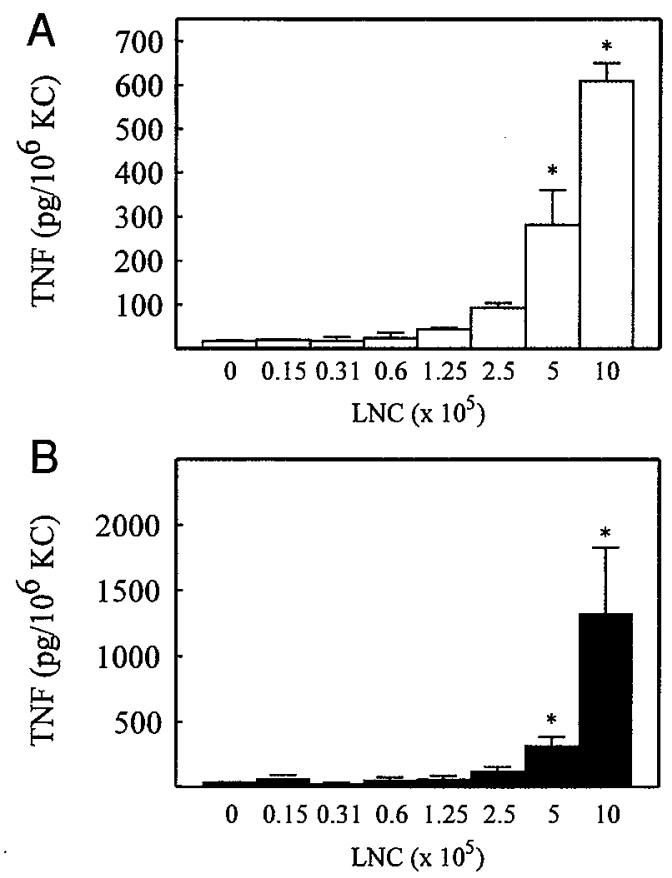

FIG. 3. Con A-induced TNF release in liver cell/LNC cocultures. $8 \times 10^{4}$ liver cells (A) or $2 \times 10^{5} \mathrm{NPC}(\mathrm{B})$ were cocultured with various concentrations of LNC, stimulated with Con A $(2 \mu \mathrm{g} / \mathrm{ml})$, and incubated at $37^{\circ} \mathrm{C}$. Sixteen hours later supernatants were removed and frozen at $-70^{\circ} \mathrm{C}$ until they were used for TNF determination. Data represent mean values $(n=3) \pm$ SEM. $* P<0.01$ vs control incubations without LNC.

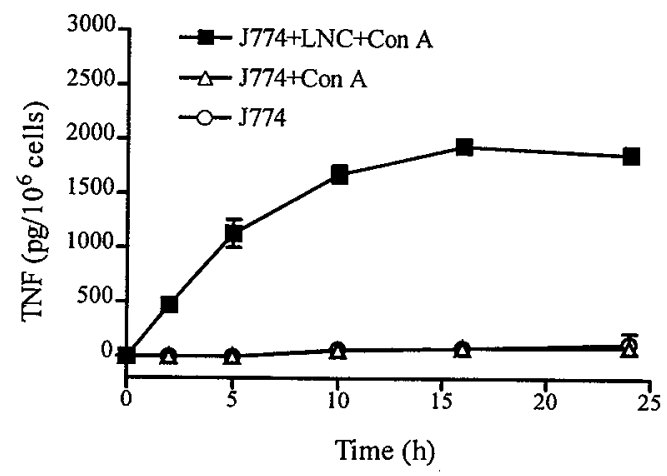

FIG. 4. Con A-induced TNF release in J774/LNC cocultures. J774 macrophages $\left(1 \times 10^{6}\right)$ were incubated with or without $1 \times 10^{6}$ LNC in the presence or absence of Con $\mathrm{A}(2 \mu \mathrm{g} / \mathrm{ml})$. At the time points indicated, supernatants were harvested for TNF determination. Data represent mean values $(n=3) \pm \mathrm{SEM}$.

selves. We incubated $0.15-1.0 \times 10^{6} \mathrm{LNC}$ either with $2 \times 10^{5} \mathrm{NPC}$ (containing $80-90 \%$ Kupffer cells) or with $8 \times 10^{4}$ liver cells (WLC) containing mainly hepatocytes $(>90 \%$ ) and $5 \%$ Kupffer cells, respectively. TNF release into the supernatant was determined $16 \mathrm{~h}$ after stimulation with $2 \mu \mathrm{g} / \mathrm{ml}$ Con A. In both liver cell/LNC coculture systems a significantly increased TNF release was noted, when at least $5 \times 10^{5} \mathrm{LNC}$ were present (Fig. 3 ). The TNF values (calculated per $10^{6}$ Kupffer cells) observed in the liver cell culture containing $5 \%$ Kupffer cells were lower compared to values measured in the Kupffer cell-enriched fraction. This effect might be due to TNF binding or degradation by hepatocytes, which may also occur in vivo [27].

These in vitro experiments demonstrate a striking capacity of the LNC/liver cell coculture system to release high amounts of TNF upon Con A stimulation. Notably, cocultures consisting of LNC from Con A resistant nude mice plus liver cells from Con A responsive mice failed to increase the basal release of TNF upon Con A stimulation (Fig. 2). Also, co-incubation with $\alpha$ MM (5 mM), a well-characterized Con A-binding sugar which blocks its mitogenic activity by competitive binding inhibition, completely abrogated the increased TNF production in the coculture system (not shown).

In order to gain definite evidence that macrophages alone are the essential cell type in the liver responsible for the LACT effect, we examined whether LNC could also communicate with a murine macrophage cell line. For this purpose, we incubated LNC with the murine macrophage cell line J774 and looked for TNF release following T cell stimulation. Figure 4 shows the time course of TNF release from Con A-stimulated J774 cells in the absence or presence of LNC. Again, the presence of LNC strongly augmented the TNF release induced by Con A compared to that in J774 cells incubated alone. The small TNF concentrations found in un- 


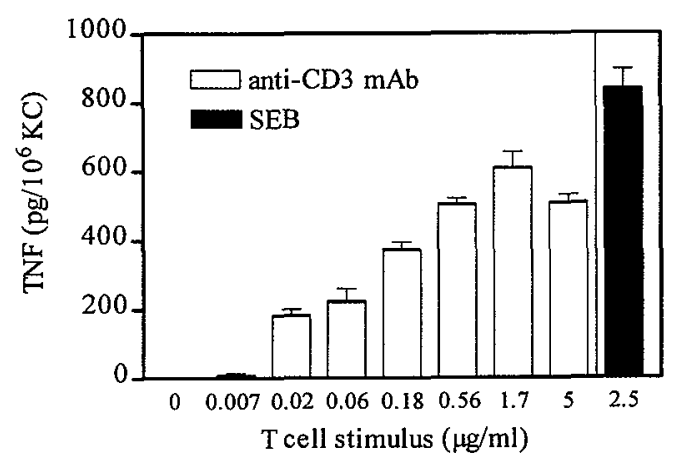

FIG. 5. Anti-CD3 $\mathrm{mAb}$ - or SEB-induced TNF release in liver cell/ LNC cocultures. Liver cells (WLC, $8 \times 10^{4} /$ well) were cocultured with LNC $\left(1 \times 10^{6} /\right.$ well $)$, stimulated with anti-CD3 mAb or SEB $(2.5 \mu \mathrm{g} /$ $\mathrm{ml}$ ), and incubated at $37^{\circ} \mathrm{C}$. Sixteen hours later supernatants were removed and frozen at $-70^{\circ} \mathrm{C}$ until they were used for TNF determination. Data represent mean values $(n=3) \pm$ SEM. No basal TNF release was noted.

treated control J774 supernatants after $24 \mathrm{~h}$ were not modulated by Con A.

Since the "LACT effect" was essentially similar when experiments were carried out in the presence or absence of hepatocytes in Kupffer cell-lymphocyte cocultures (cf. Fig. 3), studies were continued with Kupfer cell-containing liver cells (WLC) instead of the NPC fraction in order to be closer to the in vivo situation.

\section{Specificity of the LACT Effect}

We wondered whether the increased TNF release in the coculture system was a specific feature of Con A or common to different $\mathrm{T}$ cell mitogens. We used antiCD3 mAb or SEB, respectively, as polyclonal $\mathrm{T}$ cell activators instead of the lectin and examined TNF production in the liver cell/LNC coculture. The results in Fig. 5 demonstrate that an increase in TNF release was also noted when a $\mathrm{T}$ cell stimulator other than Con A, i.e., anti-CD3 mAb or SEB, was used. No TNF was detectable in supernatants of either cell population alone upon stimulation with anti-CD3 mAb or SEB, respectively (not shown).

In order to examine whether the LACT effect was specific for LNC, liver cells were co-incubated with spleen lymphocytes in the presence of $2 \mu \mathrm{g} / \mathrm{ml}$ Con A. As in the liver cell/LNC coculture system, Con A stimulated a liver cell/spleen cell coculture system to release significantly augmented amounts of TNF in the presence of at least $8 \times 10^{5}$ SLC $16 \mathrm{~h}$ after stimulation (Fig. 6A), whereas Con A stimulation of $10^{7}$ spleen cells alone failed to induce TNF release in overnight cultures $(16 \mathrm{~h})$. In addition, we investigated cells from the thymus as another source of primary murine lymphocytes in order to test their capacity to potentiate TNF release in the coculture system. When freshly prepared thymo- cytes were co-incubated with liver cells and stimulated with Con A, a significantly increased TNF release was noted, when $3 \times 10^{4}$ thymocytes or more were present (Fig. 6B). Pure thymocyte cultures containing $3 \times 10^{6}$ cells or more per $200 \mu \mathrm{l}$ released small amounts of TNF upon Con A stimulation for $16 \mathrm{~h}$. This production was, however, strongly increased by liver cell addition.

Thus, the potentiation of the TNF release capacity observed in the coculture system was neither restricted to lymph node cells as a T cell population nor to Con A as a stimulus, since the presence of lymphocytes from other sources or stimulation with alternative $\mathrm{T}$ cell activators also augmented TNF.

\section{Con A-Induced Cytokine Release in Liver Cell/LNC Cocultures}

Next we checked whether $\mathrm{T}$ cell activation in a liver cell/LNC coculture generally induced a potentiated mediator release. Therefore, we measured the release of typical T-cell-derived cytokines such as IL-2, IL-4, and IFN- $\gamma$ as well as the production of typical macrophage products such as IL-1 and IL-6.

The kinetics of Con A-induced IL-1, IL-2, IL-4, IL-6,
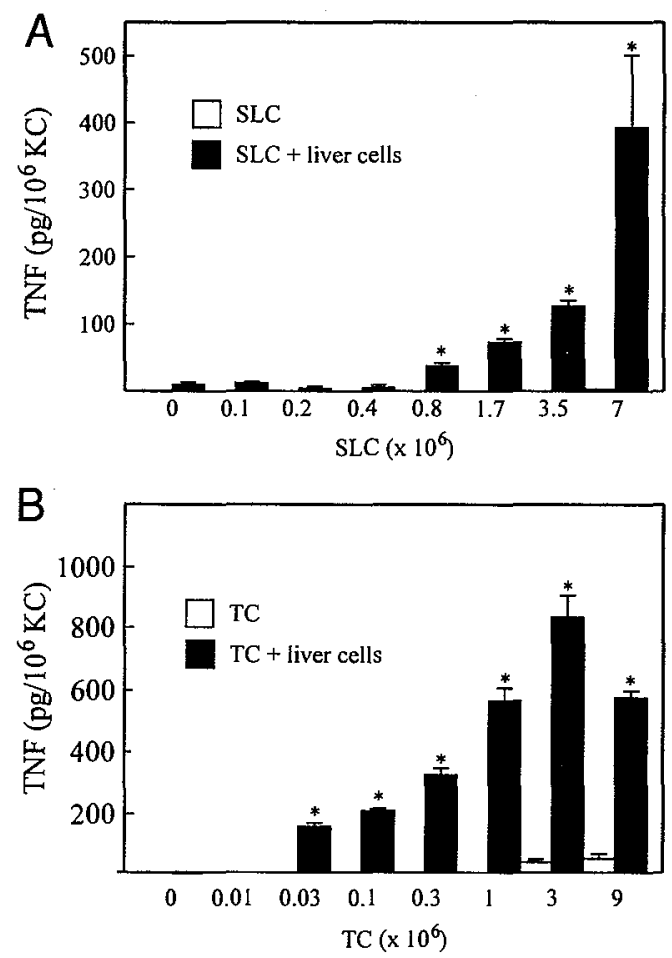

FIG. 6. TNF release from liver cell cultures incubated with Con A-stimulated spleen cells (A) or thymocytes (B). Spleen cells (SLC) or thymocytes (TC) were cultured in the presence or absence of $8 \times$ $10^{4}$ liver cells (WLC) at $37^{\circ} \mathrm{C}$ in RPMI 1640 medium containing 2 $\mu \mathrm{g} / \mathrm{ml}$ Con A. Sixteen hours later supernatants were harvested for TNF determination. Data represent mean values $(n=3) \pm \mathrm{SEM}$. $* P$ $<0.01$ vs control incubations without liver cells. 
and IFN- $\gamma$ release are shown in Fig. 7. Concentrations of both lymphokines and monokines were significantly increased $16 \mathrm{~h}$ after stimulation of liver cell/LNC cocultures compared to values obtained in control incubations of LNC or liver cells alone.

These results suggest the existence of a cellular crosstalk mechanism between liver cells and lymphocytes resulting in synergistic upregulation of cytokine release from either cell population upon Con A stimulation.

\section{Mechanisms of Augmented Cytokine Release}

The next aim was to investigate which mechanisms might underlie the augmented TNF release in cocultures of liver cells and LNC following Con A stimulation. First, the question of whether cell-cell contact between liver cells and LNC was a necessary condition for increased TNF release was addressed. Therefore, experiments were carried out using membrane inlays which separated liver cells from LNC, but still allowed cellular communication via soluble factors. The TNF concentrations measured under such separated conditions (1080 $\pm 10 \mathrm{pg} / 10^{6} \mathrm{Kupffer}$ cells) were not significantly different from values in parallel incubations without such separating membranes $\left(940 \pm 40 \mathrm{pg} / 10^{6}\right.$ Kupffer cells), indicating that direct cellular contact between liver cells and LNC was not necessary.

This result suggests that soluble factors released from Con A-activated $T$ cells are likely to account for the potentiated TNF release observed in the liver cell/ LNC coculture. Thus, we set out to examine the nature of these soluble factors in the LACT model. We tested the inhibitory actions of various monoclonal antibodies directed against murine lymphokines that have been described before to augment TNF release in other systems. Anti-IL-2 mAb as well as anti-GM-CSF mAb or combinations thereof had no effect on TNF release in our system. Addition of soluble IL-4 receptor also failed to modulate TNF production. A slight reduction (10$20 \%$ ) of TNF production was noted in some but not all experiments, when anti-IFN- $\gamma$ mAb was present in the coculture system, but the overall reduction of TNF by different monoclonal anti-IFN- $\gamma$ Ab did not reach statistical significance (data not shown). These slightly inconsistent observations prompted us to make use of mice gene-targeted for the receptor of this cytokine (ifn $\gamma-r^{\circ}$ mice) in order to clarify the possible contribution of IFN- $\gamma$ in LACT. Liver cells (WLC) and LNC from these if $n \gamma-r^{\circ}$ mice were incubated alone or together and TNF production was measured $16 \mathrm{~h}$ after stimulation of the cells with Con A (2 $\mu \mathrm{g} / \mathrm{ml})$. A 35-fold increase in TNF release was noted in this liver cell/LNC coculture compared to that in Con A-stimulated liver cells or LNC alone. This finding ultimately excludes IFN- $\gamma$ as a necessary mediator of LACT.

Thus, there must exist soluble factors different from
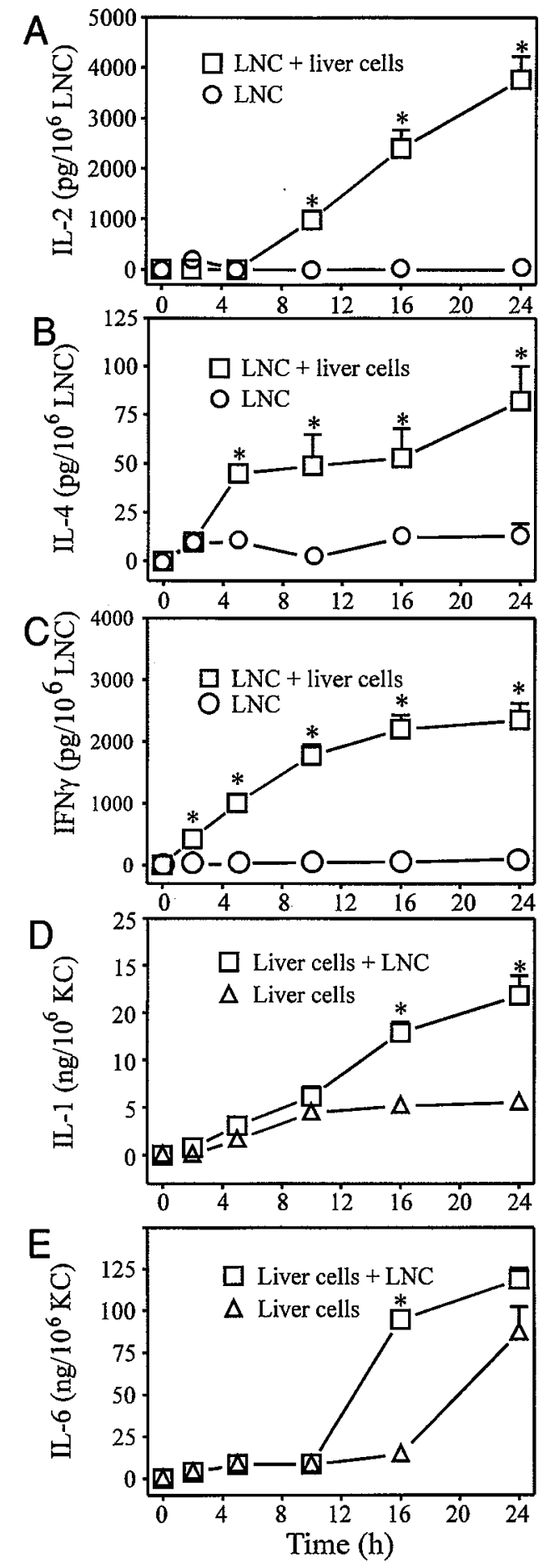

FIG. 7. Con A-induced cytokine release in liver cell/LNC cocultures. Liver cells (WLC, $8 \times 10^{4}$ ) were incubated with $1 \times 10^{6}$ LNC in RPMT 1640 medium at $37^{\circ} \mathrm{C}$ and stimulated with Con A (2 $\mu \mathrm{g} / \mathrm{ml}$ ). At the time points indicated supernatants were harvested and frozen until cytokine determination of IL-2 (A), IL-4 (B), IFN$\gamma(\mathrm{C}), \mathrm{IL}-1$ (D), and IL-6 (E). No cytokine release different from the basal release of any of these cytokines was detectable in the absence of the stimulus. Data represent mean values $(n=3) \pm$ SEM. ${ }^{*} P<0.01$ vs control incubations with LNC or liver cells alone. 


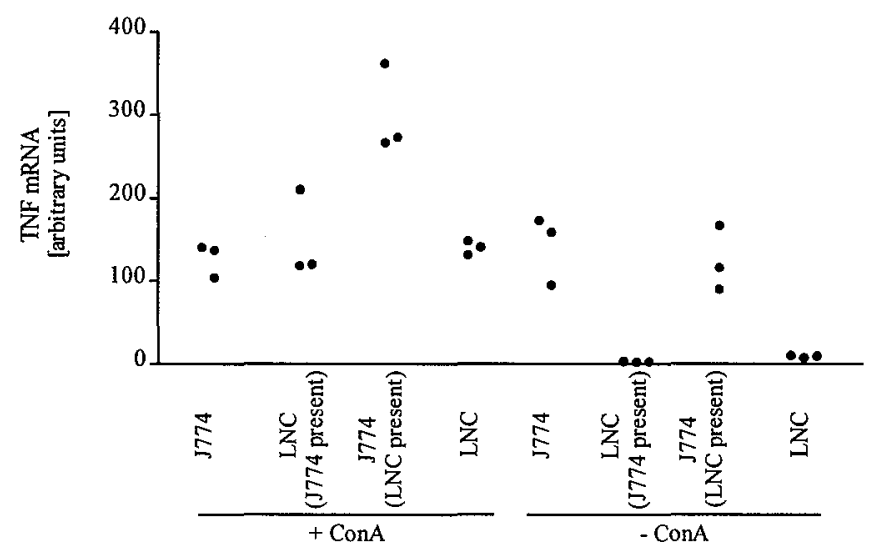

FIG. 8. Con A-induced TNF mRNA in cocultures of J774 macrophages and LNC. J774 cells $\left(1 \times 10^{6}\right)$ were seeded in $1 \mathrm{ml}$ RPMI 1640. A cell inlay was placed above the J774 cells and $1 \mathrm{ml}$ medium or $1 \mathrm{ml}$ medium containing $1 \times 10^{6}$ LNC was added to the inlay prior to Con A stimulation $(2 \mu \mathrm{g} / \mathrm{ml})$. Unstimulated cells were run in parallel. After a cultivation period of $5 \mathrm{~h}$, supernatant was collected for TNF determination. Inlays were removed, LNC and J774 were lysed, and RNA was isolated. TNF mRNA is given in arbitrary units calculated in comparison to TNF control fragment levels. Single values of experiments run in triplicate are shown.

the two most powerful enhancers of TNF release, i.e., IFN- $\gamma$ and GM-CSF, that contribute to the crosstalk between polyclonally activated $\mathrm{T}$ cells and murine macrophages. These putative factors may be short-lived, since transfer of conditioned supernatants between cell populations failed to show any significant effect.

Finally, we focused on the cellular source of TNF in the LNC/macrophage coculture system. Macrophages as well as T cells are known to be potent TNF producers under appropriate stimulatory conditions. We used membrane inlays to address this question, since this experimental setting allowed us to analyze separately TNF mRNA in either cell population. J774 cells were used for reasons of macrophage purity. They were incubated together with inlays containing LNC. Five hours after stimulation with Con $\mathrm{A}$, we measured TNF mRNA levels in J774 cells and LNC, respectively (Fig. 8). When the cell populations were cultured alone, Con A induced some mRNA for TNF in LNC within $5 \mathrm{~h}$, but no TNF protein was detectable in LNC supernatants (not shown). The basal level of TNF mRNA (Fig. 8) in J774 macrophages was not modulated by the presence of Con A. When Con A-stimulated LNC were present in inlays, however, mRNA for TNF in J774 macrophages was increased approximately threefold within $5 \mathrm{~h}$, whereas Con A-induced TNF message in LNC was not further augmented by the presence of macrophages. As a control for the functioning of the experimental system (LACT) we routinely measured TNF in the supernatants of the same cells used for RNA determination, i.e., $5 \mathrm{~h}$ after the addition of the stimulus.
TNF protein in cocultures was increased 10 -fold by Con A addition $\left(360 \pm 60 \mathrm{pg} / 10^{6}\right.$ cells vs $30 \pm 15 \mathrm{pg} / 10^{6}$ cells) whereas TNF protein in supernatants of either macrophages ( $35 \pm 15 \mathrm{pg}$ TNF $/ 10^{6}$ cells) or LNC (below the detection limit) was not increased by Con $\mathrm{A}$ addition (J774, $45 \pm 20 \mathrm{pg} \mathrm{TNF} / 10^{6}$ cells; LNC, not detectable).

Our findings suggest that increased TNF mRNA levels in macrophages following Con A stimulation of LNC/macrophage cocultures paralleled the increased release of this cytokine and argues for the macrophages as the main TNF producers in this system.

From these results we draw the conclusion that in the coculture system there exist both an early "forward" signal from the $\mathrm{T}$ cells to the liver cells, i.e., Kupffer cells, and "backward signals," directed from the liver cells to the T cells. Thus, a real "crosstalk" leads to an overall increased cytokine production.

\section{DISCUSSION}

The present paper describes an in vitro coculture system consisting of the main cell types involved in an experimental animal model of liver injury elicited by intravenous injection of Con A into mice, i.e., T cells and a mixed liver cell population [11]. We used this system for the examination of cytokine release upon Con A stimulation. The pattern and kinetics of cytokine release were quantitatively and qualitatively different from those observed in either of the individual cell populations alone. For most experiments whole liver cell cultures, containing 5\% Kupffer cells, were used instead of the purified Kupffer cells. Since the Con Astimulated potentiation of TNF production occurred in the presence or in the absence of hepatocytes, we decided to work with the hepatocyte-containing coculture system, which is closer to the in vivo situation in the liver. Indeed, the pattern of released cytokines in the coculture system consisting of liver cells and lymphocytes strongly resembled that observed in mice, where Con A injection also caused increased plasma concentrations of TNF, IL-6, IL-1, IL-2, and IFN- $\gamma[12,14]$.

Our main interest focused on TNF, the central mediator of Con A-induced liver injury in vivo $[12,14]$. This cytokine was released only in the presence of both cell types, i.e., lymphocytes plus liver cells. This fact suggests that also in vivo, large TNF quantities may be produced within the liver due to the specific interactions of lymphocytes, liver macrophages, and Con A. It is difficult to identify the TNF-producing cell population(s) in vivo, but our in vitro findings provide evidence that indeed Kupffer cells may produce the majority of circulating TNF upon interaction with $T$ cells activated by Con A injection. This suggestion is supported by the fact that macrophages are commonly regarded as the main producers of TNF [28], but they cannot be directly 
stimulated by Can A or anti-CD3 mAb to release cytokines (this study). On the other hand it is generally accepted that $\mathrm{T}$ cells are stimulated by Con $\mathrm{A}$ or antiCD3 $\mathrm{mAb}$ to proliferate and to release cytokines. Under the experimental in vitro conditions commonly used, lymphocytes produce the membrane-bound $26-\mathrm{kDa}$ form of TNF, but not the soluble 17-kDa form [29]. This notion is in agreement with our findings, i.e., that Con A did in fact induce TNF mRNA and probably expression of the membrane-bound form of this molecule in LNC, but the release of this cytokine was never observed under our experimental conditions. There may be two explanations for the in vivo findings that $\mathrm{T}$ cell activation caused the plasma release of large amounts of soluble TNF: first, an altered regulation of cytokine release from lymphocytes in this specific pathological situation, e.g., by interaction with other cell types; second, the induction of TNF release from other cells by activated $T$ cells. Based on the observation that in the presence of Con A activated lymphocytes strongly increased TNF mRNA in J774 macrophages and TNF release into the supernatant of $\mathrm{LNC/J774}$ cocultures, we favor, however, the second explanation and believe that lymphocyte-activated Kupffer cells are the main TNF producers in our system. We are, however, aware that the regulation of TNF expression also occurs on the translational level and that therefore determining mRNA levels does not allow us to ultimately exclude a minor contribution of LNC to the overall increased TNF release that we observed.

It is of importance to note that no increase in TNF production was observed when LNC from nude mice lacking functional $\mathrm{T}$ cells were cocultured with liver cells from normal mice. This is in agreement with the observation that nude mice neither released IL-2 or TNF into the circulation nor developed liver injury upon Con A injection [11, 14].

The source of lymphocytes did not seem to be critical, since thymocytes, SLC, and LNC from different sites (axillary, brachial, mesenteric, iliac, facial, inguinal) were all effective with regard to their augmentation of TNF release following Con A stimulation. Thus, it seems that any kind of freshly prepared lymphocyte is capable of acting in synergy with liver cells for the production of inflammatory mediators, providing they are mitogenically stimulated. Accessory cells such as B cells or dendritic cells may contribute to the polyclonal stimulation of $T$ cells and may therefore have some modulatory role in the in vivo model.

In contrast to findings in a 2 - to 3 -day $\mathrm{T}$ cell/macrophage coculture system, showing that direct cell-to-cell contact is necessary for intercellular communication [19], the results that were obtained in our 16-h incubation studies revealed no evidence for such a mechanism. From these results it may be suggested that also under in vivo conditions a toxic "cytokine cocktail" may lead to liver failure without necessitating direct cellular contacts.

With respect to the finding that LNC from nude mice failed to augment mediator release triggered by Con $\mathrm{A}$ in our liver cell/LNC coculture system, our results strongly suggest that $\mathrm{T}$ cell activation is the initial step in the activation cascade. In accordance with that assumption are the results that were obtained with antiCD3 mAb. In contrast to Con A, which binds to various cell types including macrophages [30,31], anti-CD3 $\mathrm{mAb}$ is a mitogen that binds exclusively to $\mathrm{T}$ cells and does not directly interact with nonlymphoid cells. When the stimulus Con A was substituted with the alternative polyclonal $\mathrm{T}$ cell activator anti-CD3 $\mathrm{mAb}$ or the superantigen SEB, a similar increase in TNF production was observed, indicating that the effect was not specific for Con A. This finding also suggests that the initial event of the LACT effect induced by Con A is due to $\mathrm{T}$ cell stimulation by the lectin.

For several reasons, IFN- $\gamma$ was the most likely candidate that could account for the early $T$ cell signaling toward the Kupffer cells, finally resulting in augmented mediator release. First, IFN- $\gamma$ was released in the coculture system (cf. Fig. 7C). Second, IFN- $\gamma$ was repeatedly shown to aggravate TNF production [3234 ] as well as TNF actions [35, 36], and recently a report was published that describes an increased TNF production by macrophages mediated in part by IFN$\gamma$ in the presence of $\gamma \delta \mathrm{T}$ cells [37]. Indeed, we found that addition of high concentrations of rmuIFN- $\gamma$ (50 $\mathrm{ng} / \mathrm{ml}$ ), i.e., 10 times higher than that produced in the coculture system, to liver cell cultures induced the release of TNF from these cells within $16 \mathrm{~h}$ (data not shown). This TNF production, however, was neither dependent on nor modulated by the presence of Con A or anti-CD3 mAb. However, the fact that LACT was working excellently in liver cell/LNC cocultures prepared from mice lacking the receptor for IFN- $\gamma$ strongly argues against a major contribution of this cytokine in our experimental system. The situation in vivo seems to be similar, since Con A still induced considerable amounts of circulating TNF in mice pretreated with a neutralizing anti-IFN- $\gamma$ Ab. This indicates that endogenous IFN- $\gamma$ is not necessary for TNF production upon Con A stimulation. Nevertheless, these mice were protected from Con A-induced hepatic injury [38]. Thus, IFN- $\gamma$ more likely represents one of the distal hepatotoxic mediators of Con A. Similar pathological actions of IFN- $\gamma$ have been demonstrated in vitro [39] and in another model of fulminant murine hepatitis in which a specific $T$ cell attack is induced in mice transgenic for hepatitis B surface antigen [40]. Thus, the soluble T-cell-derived factor(s) responsible for the augmentation of TNF release from Kupffer cells in our in vitro system remain(s) to be identified.

The increased mediator release in the liver cell/LNC 
coculture system was noted for any cytokine investigated. Considerable amounts of typical lymphokines such as IL-2, IL-4, and IFN- $\gamma$ were detectable only when both populations, i.e., liver cells and LNC, were present as was the case for the monokines IL-1 and IL6. IL-2 concentrations released from LNC alone upon Con A stimulation were below the detection limit of our bioassay under the chosen experimental conditions. It was, however, detectable after incubation of LNC with higher Con A concentrations or after time periods exceeding $24 \mathrm{~h}$ (not shown).

In summary, these observations indicate that an increased production under such coculture conditions was not selective for TNF. Moreover, these results suggest the existence of a "real" crosstalk which is initiated by Con A-induced mediator release from lymphocytes (forward signals) that in turn are "answered" by the release of backwards signals from liver cells, i.e., Kupffer cells, to lymphocytes. One of the feedback signals could be IL-1. The basal release and the rapid kinetics of IL-1, a monokine known to display various T-cellstimulating activities, could account for the increased lymphocyte mediator production observed. This synergistic upregulation finally may result in an overall augmented mediator release of both lymphocyte-derived and Kupffer cell-derived products.

Both the high amounts of TNF that were detected and the strong $\mathrm{T}$ cell dependence of the Con A-induced cytokine release in the coculture system provide evidence for an analogy to the situation of Con A-induced liver failure [12]. The Con A-stimulated liver cell//ymphocyte cocultures are suitable models for the characterization of mediators and mechanisms of leukocyte crosstalk relevant to an in vivo model of liver pathology. Like any in vitro system it represents only certain aspects of the in vivo situation. For instance, hepatocyte damage was never observed during the time span of $24 \mathrm{~h}$. However, at high concentrations ( $>20 \mu \mathrm{g} / \mathrm{ml}$ ) Con A induced hepatocyte destruction as determined by LDH release into the supernatant. This effect, however, was caused by direct interactions of the lectin with hepatocytes and may therefore not adequately reflect the in vivo situation. It was neither dependent on the presence of lymphocytes nor inhibited by the addition of TNF-neutralizing anti-TNF antibodies [41]. Thus, our coculture system seems to explain the release but not the hepatotoxic action of TNF in vivo. Both in vitro and in vivo the presence of TNF alone is not sufficient to induce hepatocyte damage, but murine hepatocytes become highly sensitive toward TNF-induced killing under the metabolic condition of transcriptional arrest [42]. However, transcriptional inhibitors and/or putative additional sensitizing factors were not present in our model system and therefore no hepatocyte destruction occurred.

The results obtained from our in vitro studies demon- strate that, when murine liver (nonparenchymal) cells and lymphocytes are cocultivated, an active communication between the cell populations is induced upon $\mathrm{T}$ cell stimulation. On the one hand the release of typical lymphokines was increased when liver cells were present. On the other hand the release of macrophage-derived products was enhanced in the presence of activated T lymphocytes. Therefore, signals in both directions, i.e., from activated $T$ cells to liver cells and back to the lymphocytes, seem to be transmitted. These signals are most likely soluble factors that build up the cytokine crosstalk between lymphocytes and liver cells that is characterized by an increased TNF release from Kupffer cells. As a result, an overall intensified answer to T cell stimulation is observed. In vivo, similar overreactions may cause high local concentrations of inflammatory mediators in the microenvironment of the liver, where the majority of Con A is bound [14]. This finally may lead to organ damage such as liver injury following massive $\mathrm{T}$ cell stimulation by Con $\mathrm{A}$.

Special thanks are addressed to Dr. A. Wendel for stimulating discussion and for providing the facilities to carry out this study. We are indebted to Dr. Michel Aguet (Genentech Inc., South San Francisco, CA, USA) and Dr. Horst Bluethmann (Hoffmann-La Roche, Basel, $\mathrm{CH}$ ) for kindly providing if $\gamma \gamma-r^{\circ}$ mice. We also thank Dr. Karlheinz Enßle (Behringwerke AG, Marburg, Germany) for the generous gift of the soluble IL-4 receptor. The perfect technical assistance of S. Otte, M. Ullmann, and G. Künstle is gratefully acknowledged. This work was supported by the Deutsche Forschungsgemeinschaft within the Sonderforschungsbereich 156 Grant We 686/131 and Grant Ti 169/3.

\section{REFERENCES}

1. Bone, R. C., Balk, R.A., Cerra, F. B., Dellinger, R.P., Fein, A. M., Knaus, W. A., Schein, R. M. H., and Sibbald, W. J. (1992) Chest 101, 1644-1655.

2. Balkwill, F. (1993) Immunol. Today 14, 149-150.

3. Tiegs, G., Wolter, M., and Wendel, A. (1989) Biochem. Pharmacol. 38, 627-631.

4. Ferran, C., Sheehan, K., Dy, M., Merite, S., Landais, P., Noel, L.-H., Grau, G., Bluestone, J., Bach, J. F., and Chatenoud, L. (1990) Eur. J. Immunol. 20, 509-515.

5. Nagaki, M., Muto, Y., Ohnishi, H., Yasuda, S., Sano, K., Naito, T., Maeda, T., Yamada, T., and Moriwaki, H. (1994) Gastroenterology 106, 450-458.

6. Huang, S., Hendriks, W., Althage, A., Hemmi, S., Bluethmann, H., Kamjio, R., Vilcek, J., Zinkernagel, R. M., and Aguet, M. (1993) Science 259, 1742-1755.

7. Sypek, J.P., Chung, C. L., Mayor, S.E.H., Subramanyam, J. M., Goldman, S. J., Sieburth, D. S., Wolf, S. F., and Schaub, R. G. (1993) J. Exp. Med. 177, 1797-1802.

8. Pfeffer, K. T., Matsuyama, T., Kündig, T. M., Wakeham, A., Kishihara, K., Shahinian, A., Wiegmann, K., Ohashi, P.S., Krönke, M., and Mak, T. W. (1993) Cell 73, 457-467.

9. Rothe, J. W., Lesslauer, W., Lötscher, H., Lang, Y., Koebel, P., Köntgen, F., Althage, A., Zinkernagel, R., Steinmetz, M., and Bluethmann, H. (1993) Nature 364, 798-802. 
10. Gantner, F., Leist, M., Jilg, S., Germann, P. G., Freudenberg, M. A., and Tiegs, G. (1995) Gastroenterology 109, 166-176.

11. Tiegs, G., Hentschel, J., and Wendel, A. (1992) J. Clin. Invest. 90, 196-203.

12. Mizuhara, H., O'Neill, E., Seki, N., Ogawa, T., Kusunoki, C., Otsuka, K., Satoh, S., Niwa, M., Senoh, H., and Fujiwara, H. (1994) J. Exp. Med. 179, 1529-1537.

13. Leist, M., Gantner, F., Künstle, G., Bohlinger, I., Tiegs, G., Bluethmann, H., and Wendel, A. (1996) Mol. Med. 2, 109-124.

14. Gantner, F., Leist, M., Lohse, A. W., Germann, P. G., and Tiegs, G. (1995) Hepatology 21, 190-198.

15. Watanabe, H., and Bannai, S. (1987) J. Exp. Med. 165, 628640.

16. Gmünder, H., Eck, H. P., Benninghoff, B., Roth, S., and Dröge, W. (1990) Cell. Immunol. 129, 32-46.

17. Herman, A., Kappler, J.W., Marrack, P., and Pullen, A.M. (1991) Annu. Rev. Immunol. 9, 745-772.

18. Isler, P., Vey, E., Zhang, J. H., and Dayer, J. M. (1993) Eur. Cytokine Netw. 4, 15-23.

19. Vey, E., Zhang, J. H., and Dayer, J. M. (1992) J. Immunol. 149, 2040-2046.

20. Lacraz, S., Isler, P., Vey, E., Welgus, H. G., and Dayer, J. M. (1994) J. Biol. Chem. 269, 22027-22033.

21. Seglen, P. O. (1973) Exp. Cell Res. 82, 391-398.

22. Klaunig, J. E., Goldblatt, P. J., Hinton, D. E., Lipsky, M. M., Chacko, J., and Trump, B. F. (1981) In Vitro 17, 913-925.

23. Espevik, T., and Nissen-Meyer, J. (1986) J. Immunol. Methods 95, 99-105.

24. Tada, H., Shiho, O., Kuroshima, K. I., Koyma, M., and Tsukamoto, K. (1986) J. Immunol. Methods 93, 157-165.

25. Hopkins, S. J., and Humphreys, M. (1989) J. Immunol. Methods 120, 271-276.

26. Platzer, C., Ode-Hakim, S., Reinke, P., Döcke, W. D., Ewert, R., and Volk, H. D. (1994) Transplantation 58, 264-268.
27. Leist, M., Auer-Barth, S., and Wendel, A. (1996) J. Pharmacol. Exp. Ther. 276, 968-976.

28. Beutler, B., and Cerami, A. (1988) Annu. Rev. Biochem. 57, 505-518.

29. Aversa, G., Punnonen, J., and de Vries, J. E. (1993) J. Exp. Med. 177, 1575-1585.

30. Ozanne, O., and Sambrook, J. (1971) Nature New Biol. 232, $156-160$

31. Cline, M. J., and Livingston, D. C. (1971) Nature New Biol. 232, $155-156$.

32. Nedwin, G. E., Svedersky, L. P., Bringman, T. S., Palladino, M. R., Jr., and Goeddel, D. V. (1985) J. Immunol. 135, 24922497.

33. Collart, M. A., Belin, D., Vassalli, J. D., de Kossodo, S., and Vassalli, P. (1986) J. Exp. Med. 164, 1791-1796.

34. Grau, G. E., Heremans, H., Piguet, P. F., Pontaire, P., Lambert, P.-H., Billiau, A., and Vassalli, P. (1989) Proc. Natl. Acad. Sci. USA 86, 5572-5574.

35. Liew, F. Y., Li, Y., and Millott, S. (1990) J. Immunol. 145, 43064310 .

36. Talmadge, J., Bowersox, O., Tribble, S. H., Lee, S. H., Shepard, M., and Liggitt, D. (1987) Am. J. Pathol. 128, 410-425.

37. Nishimura, H., Emoto, M., Hiromatsu, M., Yamamoto, S., Matsuura, K., Gomi, H., Ikeda, T., Itohara, S., and Yoshikai, Y. (1995) Eur. J. Immunol. 25, 1465-1468.

38. Küsters, S., Gantner, F., Künstle, G., and Tiegs, G. (1996) Gastroenterology 111, 462-471.

39. Morita, M., Watanabe, Y., and Akaike, T. (1995) Hepatology 21, $1585-1593$.

40. Ando, K., Moriyama, T., Guidotti, L. G., Wirth, S., Schreiber, R. D., Schlicht, H. J., Huang, S., and Chisari, F. V. (1993) $J$. Exp. Med. 178, 1541-1544.

41. Leist, M., and Wendel, A. (1996) J. Hepatol. 24, in press.

42. Leist, M., Gantner, F., Bohlinger, I., Germann, P. G., Tiegs, G., and Wendel, A. (1994) J. Immunol. 153, 1778-1786. 